Rev Biomed 2000; 11:271-275.

\title{
Identificación de Lawsonia intracellularis en 20 granjas porcinas del estado de Yucatán.
}

Jorge C. Rodríguez-Buenfil1 ${ }^{1}$, Mario J. Alvarez-Fleites ${ }^{1}$, Rafael M. Gómez-Medina².

${ }^{1}$ Facultad de Medicina Veterinaria y Zootecnia, Universidad Autónoma de Yucatán. ${ }^{2}$ Práctica Privada. Mérida, Yucatán, México.

\section{RESUMEN.}

Introducción. La Enteropatía Proliferativa Porcina es una enfermedad emergente a nivel mundial, causada por una bacteria intracelular recientemente denominada Lawsonia intracellularis. Esta bacteria afecta a todos los cerdos observandose una mayor frecuencia en la población de engorda. En Yucatán no existe información sobre la presencia y distribución de esta enfermedad.

Objetivo. Detectar la presencia de Lawsonia intracellularis en cerdos de engorda de granjas porcícolas del estado de Yucatán.

Material y Métodos. Se trabajó un total de 20 granjas porcícolas las cuales fueron seleccionadas por conveniencia. Diez unidades de muestreo fueron seleccionadas de cada granja buscando la representatividad y considerando una prevalencia del $25 \%$ un nivel de confianza de $95 \%$ y una población promedio de 2000 animales. Cada unidad fue conformada recolectando heces de 4 animales de entre 30 y $90 \mathrm{Kg}$. La técnica diagnóstica que se utilizó en el laboratorio fue la de reacción en cadena de la polimerasa.

Solicitud de sobretiros: MSc. Jorge Carlos Rodríguez Buenfil. Depto. de Epidemiología, Facultad de Medicina Veterinaria y Zootecnia, Universidad Autónoma de Yucatán. Km 15.5 Carretera Mérida-Xmatkuil, Apdo Postal 4-116, Itzimna, Mérida, Yucatán, México.

Recibido el 30/Sep./1999. Aceptado para publicación el 15/Marzo/2000.

Este artículo está disponible en http://www.uady.mx/ biomedic/rb001145.pdf

Vol. 11/No. 4/Octubre-Diciembre, 2000
Resultados. De un total de 20 granjas estudiadas 8 resultaron positivas a la presencia de Lawsonia intracellularis en la población de engorda. Esto representa un $40 \%$ de granjas infectadas con prevalencias $\geq$ al $25 \%$. Con respecto al total de unidades de muestreo $23(13 \%)$ resultaron positivas y $174(87 \%)$ resultaron negativas. Se pudo observar una mayor frecuencia de granjas positivas con poblaciones de engorda mayor a 7000 cerdos de engorda.

Conclusión. Se puede concluir que la bacteria Lawsonia intracellularis está presente en granjas porcinas del estado de Yucatán con prevalencias $\geq 25 \%$. (Rev Biomed 2000; 11:271-275)

Palabras Clave: Lawsonia intracellularis, enteropatía proliferativa porcina, cerdos de engorda, reacción en cadena de la polimerasa.

\section{SUMMARY.}

Identication of Lawsonia intracellularis in 20 pig farms in Yucatan state. 


\section{JC Rodríguez-Buenfil, MJ Alvarez-Fleites, RM Gómez-Medina.}

Introduction. Porcine proliferative enteropathy is a worlwide emergent disease caused by an intracellular bacterium recently named Lawsonia intracellularis. This bacterium affects all animals however, a higher frequency is observed in fattening pigs. There is no information about presence and distribution of this disease in Yucatan. Objective. To detect the presence of Lawsonia intracellularis in fattening pigs farms in the state of Yucatan.

Material and Methods. A total of 20 pig farms were selected for convenience. Ten sampling units were selected as representative from each farm, considering a prevalence of $25 \%$, a confidence level of $95 \%$ and a population size of 7000 animals. Each unit was formed collecting feces from 4 animals whose weight was between 30 and $90 \mathrm{Kg}$. The Polimerase Chain Reaction technique was used in the laboratory.

Results. From the total of farms studied 8 were positive to the presence of Lawsonia intracellularis within the fattening pigs population. This represents $40 \%$ of the affected farms with prevalences $\geq 25 \%$. With respect to the total of sampling units $23(13 \%)$ were positive and 174 (87\%) were negative. A higher frequency of positive farms with population $>7000$ fattening pigs was observed.

Conclusion. It is concluded that the bacterium Lawsonia intracellularis is present in pig farms in the State of Yucatan with prevalences $\geq 25 \%$.

(Rev Biomed 2000; 11:271-275)

Key Words: Lawsonia intracellularis, fattening pigs, porcine proliferative enteropathy, polimerase chain reaction.

\section{INTRODUCCIÓN.}

La industria porcícola en México se ha desarrollado grandemente convirtiéndose en una importante actividad socioeconómica para el país. En el estado de Yucatán, como en otros estados de la república, esta actividad ha cobrado mucho auge en los últimos años debido al crecimiento y mejoramiento de los sistemas de producción y a la reciente creación de tres megaproyectos porcícolas, que en su conjunto representan más del 50\% de la población de pie de cría del estado.

Las explotaciones porcícolas del estado son afectadas por la presencia de enfermedades, dentro de las que se encuentran las entéricas. Éstas repercuten en la salud de los animales y en los parámetros productivos, representando grandes pérdidas económicas para la industria porcina. Dentro de las enfermedades entéricas la Enteropatía Proliferativa Porcina (EPP) es una patología emergente a nivel mundial causada por una bacteria intracelular recientemente denominada Lawsonia intracellularis . Esta bacteria afecta a todos los animales observándose con mayor frecuencia en la población de engorda y de reemplazo. Estudios indican porcentajes de hatos infectados que van de $15 \%$ al $35 \%$ y prevalencias de $15 \%$ al $20 \%$ dentro de estos (1).

Una de las principales limitantes que se ha observado para estudiar esta enfermedad es el diagnóstico, debido a que la bacteria, por sus características, es de baja inmunogenicidad y de difícil aislamiento. El diagnóstico convencional se basa en las manifestaciones clínicas y hallazgos a la necropsia. Sin embargo McOrist (2), ha desarrollado la técnica de reacción en cadena de polimerasa para el diagnóstico en heces de los animales, la cual muestra una sensibilidad y especificidad cercana al $100 \%$.

En México existen pocos estudios sobre la presencia de esta enfermedad en el país. En Yucatán no existe información sobre la presencia y distribución de esta patología en las granjas porcinas. Por lo tanto el objetivo del presente trabajo fue detectar la presencia de Lawsonia intracellularis en cerdos de engorda de granjas porcícolas del estado de Yucatán.

\section{MATERIAL Y MÉTODOS.}

El presente estudio se realizo de Junio a Diciembre de 1997, en cerdos de engorda de 20 granjas 


\section{Lawsonia intracellularis en granjas porcinas de Yucatán.}

porcícolas de la zona henequenera del estado de Yucatán. La zona henequenera se encuentra localizada entre los paralelos $21^{\circ} 10$ latitud norte y los meridianos $89^{\circ}$ latitud este; el clima de la región es tropical sub-humedo con lluvias en verano y la temperatura media anual es del orden de $\operatorname{los} 26^{\circ} \mathrm{C}(3)$.

\section{Población animal y granjas estudiadas.}

Se trabajo un total de 20 granjas porcícolas con diferentes poblaciones animales y sistemas de producción. Las granjas fueron seleccionadas utilizando el método de muestreo por conveniencia debido a la facilidad y disponibilidad brindada por los productores (4).

Se determinó un tamaño de muestra para detectar la presencia de la enfermedad de 10 unidades de muestreo por granja, considerando una prevalencia del $25 \%$, un nivel de confianza del $95 \%$ y una población promedio de 2000 animales. Para el cálculo del tamaño de muestra se utilizo la formula citada por Martin (5):

$$
\mathrm{n}=\left[1-(1-\alpha)^{1 / d}\right][N-(D-1) / 2]
$$

Donde:

$\alpha=$ probabilidad ( nivel de confianza $=95 \%$ ) de observar cuando menos un animal enfermo en la muestra

$\mathrm{D}=$ número de animales enfermos en la población $\mathrm{N}=$ tamaño de la población.

Las unidades de muestreo fueron conformadas recolectando heces directamente del recto de 4 animales de entre 30 y $90 \mathrm{Kg}$. La selección de animales se realizó buscando la representatividad de los corrales en cada granja. Las muestras fueron depositadas en bolsas de polietileno identificándolas y conservándolas a una temperatura de $4^{\circ} \mathrm{C}$.

\section{Análisis de laboratorio.}

Las muestras fueron enviadas y analizadas en el laboratorio del Centro Nacional de
Investigaciones Disciplinarias en Microbiología de la Secretaría de Agricultura y Ganadería y Desarrollo Rural (SAGAR), ubicado en Palo Alto, estado de México.

La prueba diagnóstica que se utilizó para detectar la presencia de la bacteria fue la de reacción en cadena de polimerasa. La metodología para el desarrollo de la prueba fue la señalada por McOrist (6). El límite de detección de la prueba se ha estimado en $10^{3}$ a $10^{4}$ bacterias por gramo de heces. La prueba diagnóstica presenta una especificidad y sensibilidad cercana al $100 \%(1,7)$. La granja fue considerada positiva cuando se detectó, en al menos una unidad de muestreo, la presencia de Lawsonia intracellularis. Los datos fueron analizados utilizando estadística descriptiva.

\section{RESULTADOS.}

Del total de las 20 granjas muestreadas, 8 resultaron positivas a la presencia de Lawsonia intracellularis en la población de engorda. Esto representa un $40 \%$ de las granjas infectadas. En relación al total de unidades de muestreo $26(13 \%)$ resultaron positivas y $174(87 \%)$ resultaron negativas. Con respecto a la presencia de Lawsonia intracellularis y su relación con el tamaño de la población de engorda se pudo observar una mayor frecuencia de positivas en aquellas con poblaciones $>7000$ animales (cuadro 1).

\section{Cuadro 1}

Frecuencia de granjas positivas a la presencia de Lawsonia intracellularis con diferente población animal en engorda.

\begin{tabular}{lccc}
\hline Población de engorda & No. de granjas & \multicolumn{2}{c}{ Positivas } \\
& & No. & $\%$ \\
\hline Menores de 2000 & 3 & 0 & 0 \\
$2000-7000$ & 4 & 2 & 50 \\
Mayores a 7000 & 13 & 6 & 46 \\
\hline Totales & 20 & 8 & 40 \\
\hline
\end{tabular}

Vol. 11/No. 4/Octubre-Diciembre, 2000 


\section{JC Rodríguez-Buenfil, MJ Alvarez-Fleites, RM Gómez-Medina.}

\section{DISCUSIÓN.}

En este estudio se demuestra por primera vez la presencia de la infección por Lawsonia intracellularis en cerdos de engorda de granjas porcícolas del estado de Yucatán. Los resultados obtenidos en este trabajo indican que la frecuencia $(40 \%)$ de granjas positivas a la bacteria es mayor a la reportada en otros estudios. En España Lanza (1) reporta un 35\%; en Estados Unidos, Guerrero (8) encontró un 35\% y en Australia, Holyoake (9) señala un $30 \%$ de granjas infectadas con la bacteria. En México Morilla (10) señala un $40 \%$ de granjas positivas a EPP. Sin embargo es probable que la frecuencia de la enfermedad reportada en estos casos sea mayor debido a que en la industria porcina el uso de antimicrobianos como promotores de crecimiento es una práctica común. Algunos de estos reducen la tasa de infección, como es el caso de la tilosina y oxitetraciclina (1).

Se puede decir que el $40 \%$ de las granjas positivas a EPP tienen prevalencias $\geq$ al $25 \%$ con un nivel de confianza del $95 \%$. Este porcentaje que se puede considerar alto, está causando grandes pérdidas económicas a los productores (11). Por otro lado, con respecto al $60 \%$ de granjas donde no se detectó la presencia de la bacteria, se puede suponer que si está presente, ésta es menor al 25\% dentro de la granja. Así mismo, existe la posibilidad de que en el momento de muestreo los animales que resultaron negativos no estaban eliminando la bacteria en las heces. Esto no implica que los animales no estén infectados con Lawsonia intracellularis (1)

López (11) asocia una mayor frecuencia de EPP en granjas con buenas condiciones higiénicas y con grandes poblaciones animales. En este trabajo se pudo observar un comportamiento similar como se muestra en el (cuadro 1). Sin embargo es necesario muestrear un mayor número de granjas para demostrar estadísticamente esta diferencia.

En México el diagnóstico basado en la técnica de reacción en cadena de la polimerasa no es aún frecuente en el campo de la medicina veterinaria. El desarrollo de este trabajo y los resultados obtenidos demuestran su aplicabilidad para el diagnóstico de EPP, por lo que se convierte en la prueba antemorten de elección.

Se puede concluir que la bacteria Lawsonia intracellularis, agente causal de la EPP, está presente en granjas porcinas del estado de Yucatán con prevalencia $\geq$ al $25 \%$. Sin embargo, para un mejor entendimiento de la biología de esta enfermedad, es necesario realizar estudios epidemiológicos que clarifiquen aspectos como duración de eliminación de la bacteria en heces, presencia de animales portadores o con infección latente y factores de riesgo asociados a la enfermedad. Esta información sustentará de una manera racional las estrategias de control contra esta enfermedad.

\section{REFERENCIAS.}

1.- Lanza I, Pozo J, Muñoz M, Rubio P, Cármenes P. Epidemiological study of porcine proliferative enteropathy in Spain. Proceeding of the 14 th International Pig Veterinary Society Congress. Bologna, Italy; 1996. p 259.

2.- McOrist S, Gebhart C, Boid R, Barns S.M. Characterización of lawsonia intracelularis, the obligately intracelularis bacterium of porcine proliferative. Int $\mathbf{J}$ System Bacteriol 1995; 45: 820-5

3.- Duch-Gary J. "La conformación territorial del estado de Yucatán". Universidad Autónoma de Chapingo. 1998; p. 120-87.

4.- Thrusfield M. Epidemiología Veterinaria. Zaragosa: Acribia; 1990. p 191-6.

5.- Martin SW, Meek AH, Willeberg P. Veterinary Epidemiology. Principles and Methods. First edition. Ames: Iowa State University; 1987. p 73-74

6.- McOrist S, Gebhart CJ, Lawson GHK. Polimerase chain reaction for diagnosis of proliferative enterophaty. Vet Microbiol 1994; 41: 205-12.

7.-McOrist S. Enteropatía Proliferativa del Porcino "Ileitis".Pigs especial Misset. 1996; 8-9.

8.- Guerrero R. Temas de Actualidad para la industria porcina 1996.México; Ed. Midia Relaciones; 1996. p. 2618.

\section{Revista Biomédica}


Lawsonia intracellularis en granjas porcinas de Yucatán.

9.- Holyoake PK, Cutler RS. Outbreaks of proliferative haemorragic enteropathy on two pigs farms. Aust Vet J 1995; 71: 308-9.

10.- Morillla A. Ileitis o Enteropatía Proliferativa Porcina. Manual para el control de las enfermedades infecciosas de los cerdos. México: Ed. Inifap-Sagar; 1996. p 159-61.

11.- López EJ. Métodos para el Control de la Enteropatía Proliferativa Porcina. (Ileitis).Cerdos Swine Publicaciones Midia Relaciones 1999; (18):23-6. 